\title{
USING AHP IN QFD - THE IMPACT OF THE NEW ISO 16355 STANDARD
}

\author{
Thomas Fehlmann, QFD Architekt, Euro Project Office \\ Glenn Mazur, QFD Red Belt ${ }^{\circledR}$ and QFD Architekt, QFD Institute
}

\begin{abstract}
Traditional Quality Function Deployment (QFD) uses weights - percentages of a total - to describe priorities for customer's needs and technical solution approaches. Since AHP works with profiles - vectors of unit length one - it is possible to add, subtract and compare profiles, while weights yield wrong results when added, subtracted or compared. When using AHP for profiling customer's needs for use with QFD, this is an incompatibility that might lead to failures. The new ISO standard 16335 introduces ratio scales and profiles in QFD.

Moreover, the method proposed by Saaty to calculate priority profiles in AHP is also applicable to modern QFD. The new ISO 16355 suggests ratio scales in QFD matrices instead of the traditional ordinal correlation strength indicators. AHP is used in many steps in QFD, but this paper will focus primarily on the House of Quality matrix.

Keywords: AHP, QFD, Comprehensive QFD, Six Sigma, Eigenvectors, Linear Algebra, ISO 16355.
\end{abstract}

\section{Introduction}

Quality function deployment (QFD) originated in Japan in the 1960s as an extension of statistical process control (SPC) and total quality management (TQM) applied to new product development to improve quality and thus customer satisfaction. At that time, Japan was quickly improving its manufacturing capabilities after the devastation of World War II, saw their next step as improving the basic designs prior to the manufacturing phase. This became more urgent with the onset of the oil crisis in the early 1970s when Japan's smaller, more fuel efficient automobiles became globally popular but were equally panned for their poor quality and performance. QFD was conceived to create a network of quality assurance activities that spanned the total organization - from marketing to engineering to manufacturing and production to suppliers. The purpose of this network was to create a common focus based on what was most important to customers, and then align these organizational functions by translating customer importance into engineering, manufacturing, production, and supplier importance.

These translations were initially done using cause-and-effect diagrams (aka fishbone diagrams due to their skeletal appearance) with the effect representing the customer need and the causal factors representing design and build quality requirements strongly related to achieving those needs to be met. While cause-and-effect diagrams were a powerful TQM tool for problem solving to identify the causes of undesirable effects (negative quality), Bridgestone Tire's Kiyotaka Oshiumi (Oshiumi, 1966) was first to repurpose them for identifying the causes of desirable effects (positive quality demanded by customers). For example, a problem solving diagram could identify the causes of undesirable vibration, while 
a QFD diagram could identify the causes of a smooth feeling ride as shown in Figure 1. Since each diagram was composed of a single effect and multiple causal factors, each customer need required its own diagram. Causal factors commonly related to more than one need.

Figure 1. Cause-and-effect diagram for tire design (Mizuno \& Akao, 1994)

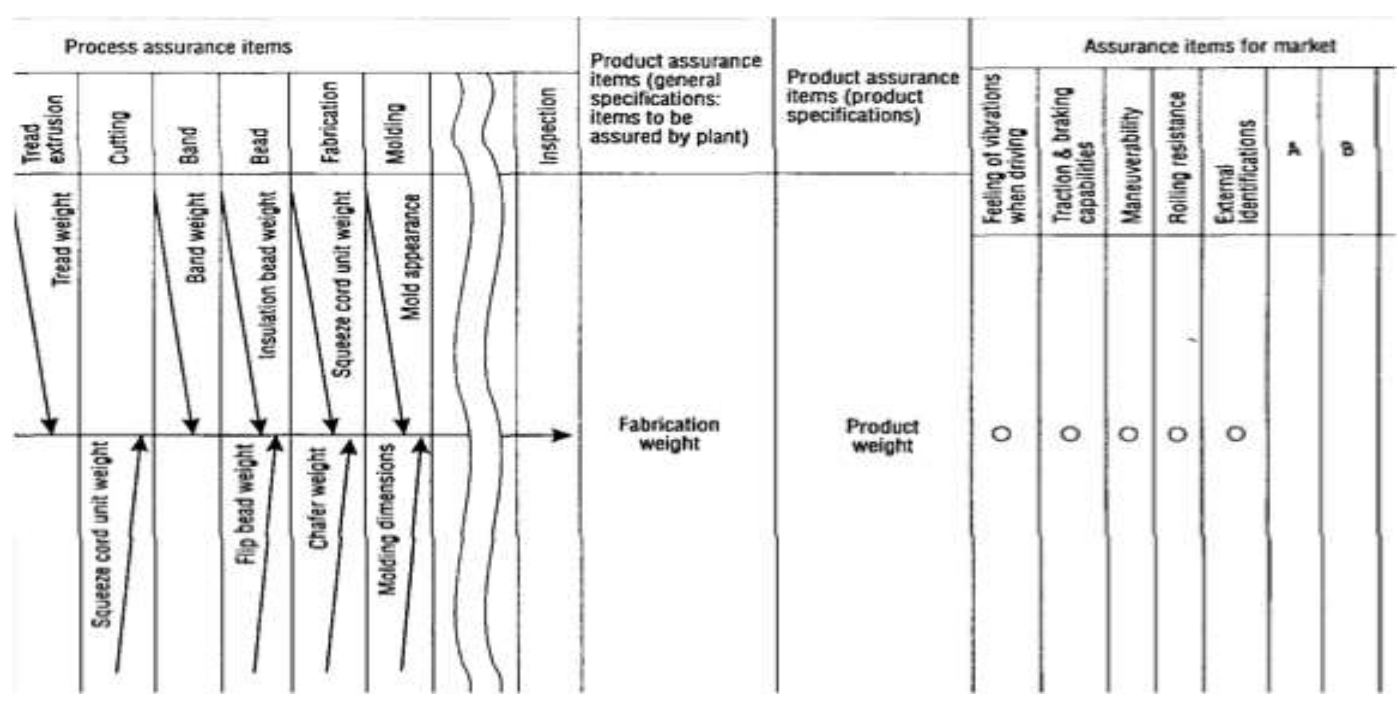

By 1972, QFD was being applied to more complex products such as oil tankers, which had hundreds of customer needs and quality requirements. Hundreds of cause-and-effect diagrams with shared causal factors became unmanageable and were soon organized into a two-dimensional matrix, not necessarily square, with the effects on one axis and the causal factors on the other. The intersections of the rows and columns were used to indicate if a relationship existed and later to quantify the strength of the relationship (Suzuki, 1972). The most well-known matrix was later dubbed the House of Quality due to the various "rooms" added to benchmark competitive alternatives and specifications.

\section{Figure 2. First example of QFD matrix (Suzuki, 1972)}

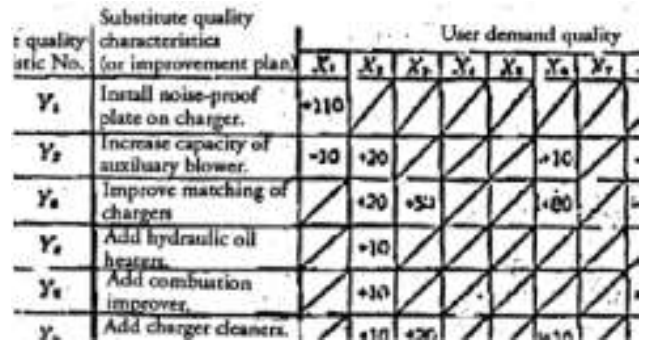

Within each matrix, the relationship strength was used to transform both the information and the priorities from the input axis to the output axis. The relationship strengths were weighted by the row priorities and then summed for column to create column priorities. Since the abacus was common used to calculate sums in 1960s Japan, relationship strengths were often expressed as ordinal scale integers, since absolute scales with ratio values would be difficult to calculated. Further, since some columns had positive relationships (ex. noise and insulation) and other columns had negative relationships (ex. weight and fuel con- 
sumption), the sum of columns with many positive and negative numbers risked them canceling each other out, rather than signifying areas demanding further research. The use of absolute values was used subsequently.

The matrices were then linked together such that the output of one matrix became the input of the next level of design detail, from system level design to components to production and assembly. By the mid-1980s, additional matrices related to technology and innovation, target costing, and reliability helped QFD evolve into a more comprehensive approach strengthening other phases of product development as shown in Figure 3. These matrices were called "deployments" indicating the importance of advanced planning and accurate information.

Figure 3. Comprehensive QFD including quality, technology, cost, and reliability deployments (Akao, 1990)

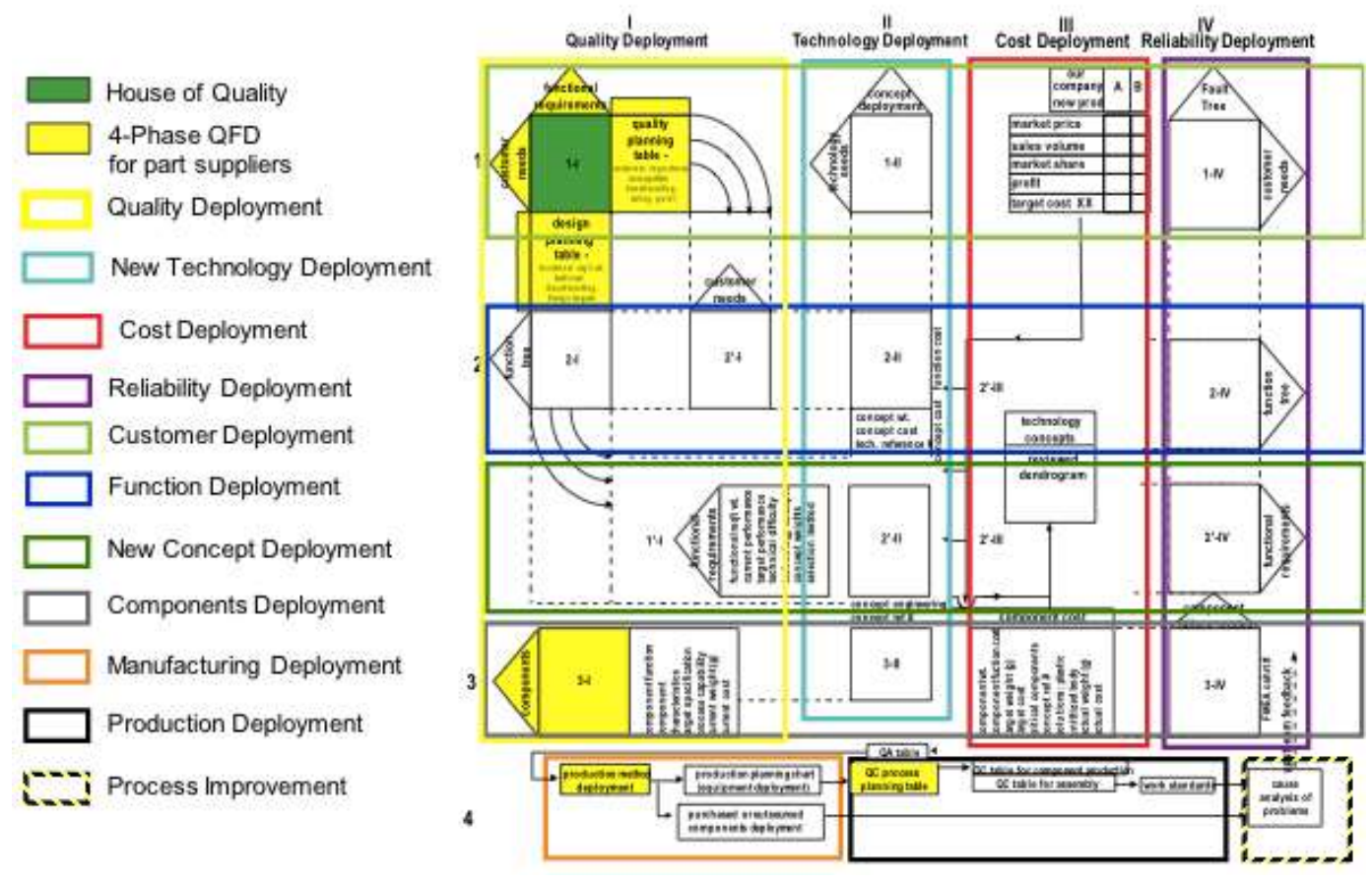

\section{Background of AHP within QFD}

As stated above, transformation of relationships within QFD matrices was problematic. The analytic hierarchy process (AHP) was considered for a solution by Nakui (Nakui, 1987). Subsequently, AHP is now more fully integrated into QFD as a preferred method for solving the subjective decision problems involving prioritizing the voice of the customer and transferring it into the voice of engineering, manufacturing (or more generally, building), production (or more generally, implementation), and supplier quality.

Saaty (Saaty, 2003) discovered the advantages of using Eigenvectors for solving decision problems using the AHP. Fehlmann (Fehlmann, 2003) noticed that QFD matrices should also use ratio scale, thus enabling the power of linear algebra to find optimum technical solutions. Together with Kranich (Fehlmann \& Kranich, 2016 - to appear), a mathematical method was developed to compute technical solution profiles with Eigenvectors similar to 
Saaty. AHP is the method of choice for prioritizing customer's needs' as the goal profile, where customers are not at hand for more direct methods such as the Gemba (Johnson \& Mazur, 2008). This is important for instance in product design and improvement.

\section{Objectives}

This paper compares traditional approaches with the new standards set by ISO 16335 (ISO 16355-1:2015, 2015) and investigates typical combinations of AHP with QFD. It demonstrates how the traditional methods can become misleading and explains the insights gained by the Eigenvector theory. These insights become more critical in today's product development environment where limited resources constrain the efforts of organizations to address only the most critical customer needs. A sound mathematical approach to separating the critical few from the trivial many is desired.

Further, when transferring priority from customer needs to functional requirements, it is useful to have values that are on an absolute scale where numbers are in ratio to each other, as these fully support the mathematical functions of addition, subtraction, multiplication, and division.

\section{Methodology}

First, the difference between weights and profiles must be clarified. Weights are percentages of $100 \%$; they sum up to $100 \%$. Profiles are vectors whose Euclidian length is one.

Let $\boldsymbol{y}=\left\langle y_{1}, \ldots, y_{m}\right\rangle$ be a vector of dimension $m$. The Euclidian norm for vectors is:

$$
\|\boldsymbol{y}\|=\sqrt{\sum_{j=1}^{m} y_{j}{ }^{2}}
$$

A vector becomes a profile by dividing components through its length:

$$
\boldsymbol{y}^{\prime}=\frac{\boldsymbol{y}}{\|\boldsymbol{y}\|}=\left\langle\frac{y_{1}}{\|\boldsymbol{y}\|}, \ldots, \frac{y_{m}}{\|\boldsymbol{y}\|}\right\rangle
$$

Normalized profiles can be added, subtracted and compared as any other vector. Result vectors become profiles again be normalization. Profiles allow for statistical methods.

QFD problems of the form $\boldsymbol{y}=\boldsymbol{A x}$, where $\boldsymbol{y}$ is the goal profile and $\boldsymbol{x}$ the product requirements can be solved by looking at the matrix product $\boldsymbol{A} \boldsymbol{A}^{\top}$ where $\boldsymbol{A}^{\top}$ is the transpose of $\boldsymbol{A}$. Thus, if $\boldsymbol{A} \boldsymbol{A}^{\top}$ has a principal eigenvector $\boldsymbol{\tau}_{\boldsymbol{y}}$, a consistent solution $\boldsymbol{x}$ is found by

$$
\boldsymbol{A} \boldsymbol{A}^{\top} \boldsymbol{\tau}_{\boldsymbol{y}}=\boldsymbol{\tau}_{\boldsymbol{y}} \Rightarrow \boldsymbol{x}=\boldsymbol{A}^{\top} \boldsymbol{\tau}_{\boldsymbol{y}}
$$

under condition that the Convergence Gap $\left\|\boldsymbol{y}-\boldsymbol{\tau}_{\boldsymbol{y}}\right\|$ becomes small enough. This statistical test prevents against bad mathematics (Mazur, 2014) as observed in certain traditional QFD practices, especially in priority comparisons and combinations. 


\section{Applications of AHP in the House of Quality}

\subsection{House of Quality}

Although no longer essential in the modern QFD process, the House of Quality is a powerful approach to transferring priorities and information from customer needs into functional requirements (Akao, 1990). As shown in the upper left corner of Figure 3, it is the gateway to product information flow-down from specifications to innovation to cost, reliability, and finally to build and commercialization activities. In other words, priorities calculated in the House of Quality are transferred into priorities in all the later phases of design and development. Thus, the accuracy of these later priorities rely on the accuracy of the initial inputs - customer needs priorities. Strong mathematical models developed with AHP produce priorities that are in ratio scale and are more accurate than the ordinal scale priorities used in early QFD studies.

The multicriteria decision making model (MCDM) of AHP can be adapted for the House of Quality. The MCDM is used to synthesize a set of prioritized criteria into a set of prioritized alternatives to achieve those criteria. In the House of Quality, the criteria are customer needs and the alternatives are the functional requirements. Other matrices in Figure 1 follow a pattern of using the alternatives of one matrix as criteria for the next in sequence, while introducing other information sets as new alternatives.

\subsection{Using AHP to prioritize customer needs}

Customer needs represent the judgment criteria that customers use to determine if a new product will be more satisfying than their current product or a product from an alternative provider.

Key to a successful product development process is the focus and alignment of scarce project resources (time, people, money) on what matters most to customers, since satisfying those needs is what drives customer value, and hence sales turnover and profit. Using the scarce resources to solve the most important customer needs is often preferred to solving a basket of less important needs. Thus, determination of importance with some accuracy is key.

Early QFD studies in the 1970s recognized the mathematical limitations of ordinal scales and defaulted to assigning alphabetical rankings of $a, b$, and $\mathrm{c}$ to convey importance, as shown in . However, as QFD was applied to larger, more complex products, the number of needs grew to as many as $900-1,000$, thus rendering the alphabetical rankings unwieldly and a numerical model more desirable. When using AHP was proposed by Nakui, the solution to meaningful mathematical modeling in QFD was realized.

Figure 4. Using a, b, c for prioritization

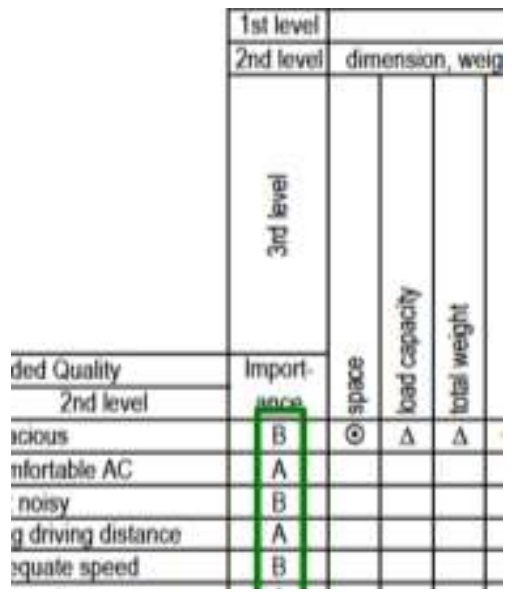




\subsubsection{Acquiring customer needs to be used for MCDM criteria}

One important consideration in MCDM is that the decision makers have knowledge of the subject. For customer needs, this mean customers, not the organization making the product. In many instances, there may be a value chain of customers that includes buyers, installers, users, maintenance, and others. ISO 16355 (ISO 16355-2:2016, 2016) recommends that these customers be the source of both the needs and the priorities. Thus, installers only prioritize installer needs, etc. These customers can also be prioritized using AHP as described in the standard, but this is beyond the scope of this paper.

Another consideration in MCDM is that the sets of criterial and alternatives be independent of each other. In the House of Quality, this means that a customer need is independent of functional requirements. For example, a café customer might say "I want a hot cup of coffee" but this is not a customer need since it describes an attribute of the coffee - hot. In QFD, these must be translated into product independent needs, such as "I want to feel warm inside because it is cold outside." This is essential for several reasons. First, it is possible to offer coffee that is too hot to drink, and thus the customer cannot get warm. Second, there may be other attributes besides "hot" needed to create warmth. Third, there may be other solutions besides temperature to make the customer feel warm inside, such as alcohol or spice. Thus, product-independence of customer needs is essential for proper specifications and innovative solutions in the new product.

\subsubsection{Structuring customer needs}

In AHP, problems are structured as a hierarchy and in MCDM the hierarchy is used to organize "perceptions, feelings, judgments, and memories" that influence the decision. (Saaty \& Peniwati, 2008) A well-structured hierarchy exhibits MECE or mutually exclusive, collectively exhaustive elements that protects against double counting and missing choices. An example of mutually exclusive in the same hierarchical level would be apple vs. pear, while a violation would be apple vs. fruit. An example of missing elements would be in the class of drupe fruits (have a center stone), the sub-categories list peaches and apricots, but missing are plums and cherries, which can be logically added once the category is named.

In QFD, the customer needs are perceptions, feelings, judgments, and memories that represent benefits the customer seeks to address their life or work problems, opportunities, and image concerns. Once acquired, each customer type along the value chain makes a hierarchy of their needs only, and is asked to check if the hierarchy exhibits MECE, and make appropriate adjustments. Part 4 of the standard provides detailed guidance and examples of this step. (ISO 16355-4:2016, 2016)

\subsubsection{Prioritizing customer needs}

Once the customer needs hierarchy is constructed and adjusted, the customer is asked to use pairwise comparison to prioritize their needs. Making comparisons are a skill intrinsic to humans, and do not require much analytic or mathematical skill. Imagine a shopper holding a melon in each hand to determine which is heavier. What AHP facilitates is taking these comparisons of qualitative customer needs and deriving a quantitative representation in relative numbers. 
In QFD, where there may be hundreds of customer needs at the tertiary level of the hierarchy, the number of comparisons can easily overwhelm. Unlike decision makers in an organization whose job it is to reach consensus and work together, customers have no such obligation. Thus, presenting a full set of comparisons risks the customer becoming uncooperative or tiring and just filling in numbers to get it over with.

Part 4 of the standard offers guidance on this. First, customers are asked to prioritize the customer needs hierarchy beginning with the most abstract level (usually 5-7 elements). Five elements present only ten comparisons $\left(n^{2}-n\right) / 2$ which a person can easily complete in just a few minutes. Then, customers are asked to prioritize the next level branches of only those nodes with high priority. This is repeated to the next level "children" whose local priorities can be multiplied by the priorities of their parents to calculate a global priority.

Since most products seek multiple customers, it may not be possible to have $100 \%$ of them vote their preferences with pairwise comparisons. Part 4 of the standard includes statistical methods for calculating sample size according to size of the population, the likelihood that the participant represents the target segment, the tolerable margin of error, and desired confidence level. With multiple respondents, numbers may represent different levels of importance; pessimists may score to the bottom of the scale, optimists to the top, and fencesitters around the middle. Using a verbal scale ranging from the two elements in the pair having equal priority to one being extremely more important than the other (to improve) is recommended. The number of levels has been recommended at nine levels, which Saaty describes as nine being the upper limit because one can divide distinctions into the three categories of high, medium, low and each of these into three categories of high, medium and low thus yielding nine grades of distinction. (Saaty, 2007)

Figure 5 is an example of a pairwise comparison matrix for tertiary customer needs in a customer relations management software app. (Stansfield, et al., 2010) The right most column indicates the priorities from the AHP calculation. These are then applied to the hierarchy where local and global weights are displayed, as shown in Figure 2.

\section{Figure 5. Pairwise comparison of customer needs for a customer relations} management app

\begin{tabular}{|c|c|c|c|c|}
\hline 1.1 Customer Understanding & 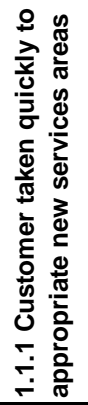 & 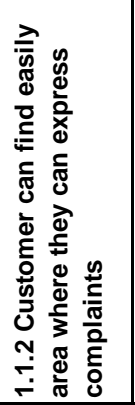 & 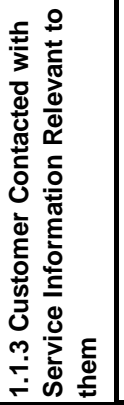 & \\
\hline $\begin{array}{l}\text { 1.1.1 Customer taken quickly to appropriate new services } \\
\text { areas }\end{array}$ & 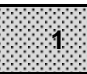 & $1 / 2$ & $1 / 3$ & 0,164 \\
\hline $\begin{array}{l}\text { 1.1.2 Customer can find easily area where they can express } \\
\text { complaints }\end{array}$ & 2 & 1 & $1 / 2$ & 0,297 \\
\hline $\begin{array}{l}\text { 1.1.3 Customer Contacted with Service Information Relevant to } \\
\text { them }\end{array}$ & 3 & 2 & 1 & 0,539 \\
\hline
\end{tabular}


Figure 6. Weighted customer needs hierarchy for customer management app (partial)

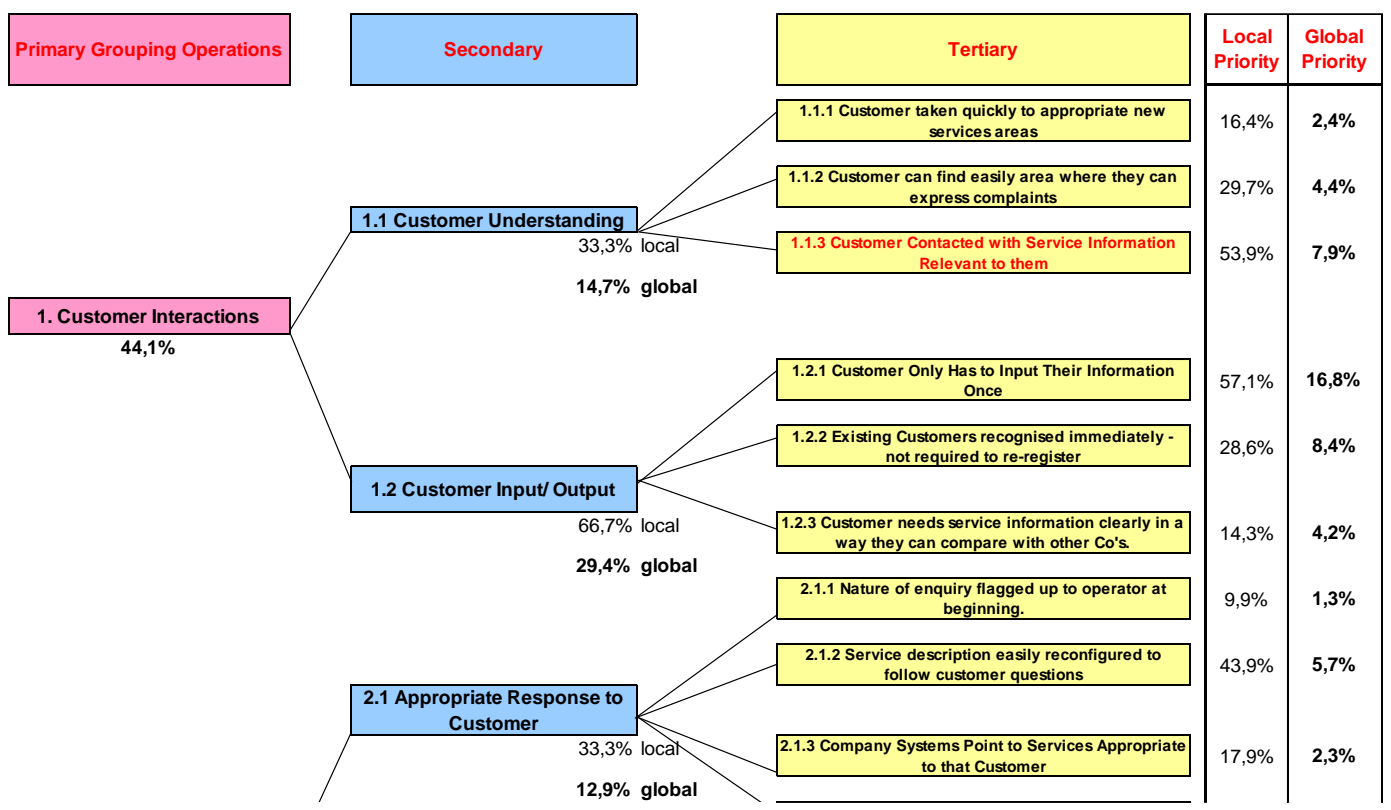

\subsection{Using AHP to transfer customer needs priorities into functional requirements priorities}

Transferring one data set and priorities to prioritize another data set has similarities with employing criteria to synthesize a decision on alternatives in MCDM. In QFD, the criteria are the customer needs, formed into a hierarchy, and then prioritized. The alternatives are the product requirements evaluated against the prioritized criteria, and the product requirement weights are derived as described below. In QFD, this is called the House of Quality.

The House of Quality matrix is thus used to transfer the information and priorities of the customer needs into product requirements and priorities. Product requirements may include both functional and non-functional requirements according to the project. QFD defines these requirements as what a product must do or be, independent of the enabling technology. This is consistent with the systems engineering concept of "solution space" where such technology independence offers greater degrees of freedom in innovating new and better ways to perform the functions. Typically, the customer needs are entered into the rows of the matrix and the requirements into the columns. In the intersecting cells, the QFD team then makes a judgment as to the strength of the relationship or contribution of the product requirement to achieving the customer need. In classical QFD, the positive and negative values shown in Figure 2 were replaced with absolute value integers which in Japan were settled on three levels of $1,3,5$. When the U.S. automotive industry adopted QFD in the early 1980s, they changed the three levels to 1,3,9 in order to stretch the space between the calculated product requirement weights. 
The product requirement weights are calculated as

$$
W_{j}=\sum_{i=1}^{n} X_{i} a_{i j}
$$

where:

- $X_{i}=$ the priority of the row item (e.g., customer need priority in the house of quality)

- $a_{i j}=$ the strength of the relationship

Since the QFD team is asked to take qualitative customer needs and priorities and judge how their relationship with more quantitative product requirements using the above calculation, AHP offers an absolute scale with numbers in ratio to each other that improves the accuracy better than ordinal scale numbers. On an abacus, such calculations would be onerous, especially in a complex product with 1,000 customer needs and 1,000 product requirements yielding 1,000,000 relations to judge and calculate. With a PC and spreadsheet software, the effort takes only a moment to calculate once and then cut-and-paste across the entire matrix. Nakui's integration of AHP into QFD was heralded as a breakthrough in Japan in 1987, providing not only ease of calculation but the added accuracy of ratio scale math.

The large number of relationships to judge in a QFD matrix make it easiest to use an absolute or expert scale, rather than direct or pairwise judgments. Direct judgments would require some type of correlation test between each customer need and product requirement with enough samples to satisfy concerns for error. Given that the customer needs are typically subjective and the product requirements are not technology-specific, the task would be overwhelming for all but the riskiest projects (such as a manned flight to Mars). Likewise, pairwise comparisons of all product requirements against each criterion would be an exhausting exercise, by the end of which, participants would be agreeing to any value just to go home. An absolute expert judgment scale has been used in Japan since the 1970s with success sufficient to recommend it in the ISO standard, with the modifications described below.

\subsubsection{Displaying QFD relationship weights with AHP judgments}

Part 5 of the standard provides detailed guidance on building a House of Quality and the related matrices in Comprehensive QFD shown in Figure 3. Comprehensive QFD including quality, technology, cost, and reliability deployments Figure 3. (ISO 16355-5:2016, 2016) The number of levels was expanded from three to nine, to take advantage of the human cognitive skills discussed above. The visual display of the matrix also lends itself to relationship patterns that are useful in diagnosing the quality of the analysis, such as MECE violations that escaped earlier scrutiny. The three Japanese favorite symbols did not lend themselves to expansion to nine levels so the standard adopted the widely recognized cloud cover symbols of

$$
W \bigcirc W-M \odot M \bullet M-S \bullet S \bullet S-V \supset V \bullet V-X \bullet X \bullet
$$


and applied a verbal scale with similar wording to AHP's pairwise comparisons, mainly weak $(\mathrm{W})$, moderate $(\mathrm{M})$, strong $(\mathrm{S})$, very strong $(\mathrm{V})$, or extremely strong $(\mathrm{X})$, as well as intervals such as weak-to-moderate (W-M), and so forth.

\subsubsection{Quantifying QFD relationship weights with AHP}

Part 5 of the standard also provides ratio scale values for each of the nine relationship levels to replace the ordinal integers of $1,3,5$ and $1,3,9$. These values were calculated from the AHP pairwise comparison of the nine verbal levels to themselves shown in Figure 7. The results were recalculated so that the maximum level of extremely strong relationship was 1,000 (shown with decimal commas) and with all other levels in ratio, as $\mathrm{W}(0,059), \mathrm{W}-\mathrm{M}$ $(0,079), \mathrm{M}(0,112), \mathrm{M}-\mathrm{S}(0,162), \mathrm{S}(0,237), \mathrm{S}-\mathrm{V}(0,344), \mathrm{V}(0,498), \mathrm{V}-\mathrm{X}(0,712), \mathrm{X}$ $(1,000)$.

\section{Figure 7 Pairwise comparison of nine QFD relationship levels}

\begin{tabular}{|c|c|c|c|c|c|c|c|c|c|}
\hline & Extreme & V5.E & Very wong & 5.15 & Etreng & M.5 & Moderate & W.M & Wed \\
\hline Entrene & 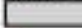 & 2 & 3 & 4 & 5 & 6 & 7 & 8 & 9 \\
\hline IS-E & 0.5 & & 2 & 3 & 4 & 5 & 6 & 7 & 8 \\
\hline Voy strong & 0.335 & 05 & & 2 & 3 & 4 & 3 & e & $?$ \\
\hline $5-15$ & 0.25 & 8331 & 0.5 & & 2 & 3 & 4 & 5 & 6 \\
\hline Strong & 0.2 & 025 & 0333 & 25 & & $z$ & 3 & 4 & 3 \\
\hline M-5: & 0.257 & 0.2 & 0.25 & Q.333 & 0.5 & & 2 & 3 & 4 \\
\hline Modence: & 0.243 & 0.297 & 0.2 & 0.25 & 0331 & 0.5 & & 2 & 3 \\
\hline$w-M$ & 0.125 & D.tas & 0.167 & 02 & 0.25 & 6.213 & 0.5 . & & 2 \\
\hline Weak & 0.111 & 0.125 & 0143 & 0.167 & 02 & 0.25 & 0.333 & 03 & \\
\hline
\end{tabular}

\subsubsection{Ideal and proportional distribution}

As in MCDM, QFD matrices use different distribution methods to synthesize the product requirement weights including independent, ideal, and proportional distributions. The formula above in 5.3 is the independent distribution and is preferred when trying to transfer customer needs priorities into product requirement priorities. There are other cases where a limiting constraint such as target price, weight (mass), or power must be allocated to subsystems or components, and proportional distribution is preferred. Guidelines for different distribution methods are detailed in Part 5 of the standard. (ISO 16355-5:2016, 2016)

\subsubsection{Building the modern House of Quality}

As explained above, the classical House of Quality suffered from ordinal scale mathematical calculations hampered by the limited availability of PCs and spreadsheets to product development engineers in the 1970s and early 1980s when QFD was exported from Japan. These limitations were easily remedied in the mid-1980s when PCs, spreadsheets, and DOS based AHP programs became available. Figure 8 continues the case study of the customer relationships management app with the House of Quality showing tertiary customer needs and their priorities transferred into product functional requirement priorities. (Stansfield, et al., 2010) A summary of the steps to building this House of Quality are as follows:

1. The QFD teams meets with customers to acquire their "voice." These voices are translated into product independent benefits, called customer needs.

2. The customers are asked to prioritize their needs by first constructing a hierarchy and then using pairwise comparisons and AHP. These are entered into the rows of the House of Quality. 
3. Functional requirements are derived by the QFD team and entered into the columns of the House of Quality.

4. The QFD teams judges the relationship strength or degree of contribution of each functional requirement to each need, using a verbal scale. Symbols are used to represent this strength. The symbols are also assigned absolute values in ratio scale by way of AHP.

5. The spreadsheet multiplies the absolute value of the symbol by the priority of the customer need, and sums these products column-by-column for each functional requirement (called an absolute weight at the bottom of the matrix), using independent distribution. These are then normalized to $100 \%$ (called a functional requirement weight at the bottom of the matrix).

Figure 8 House of Quality for customer relationship management app
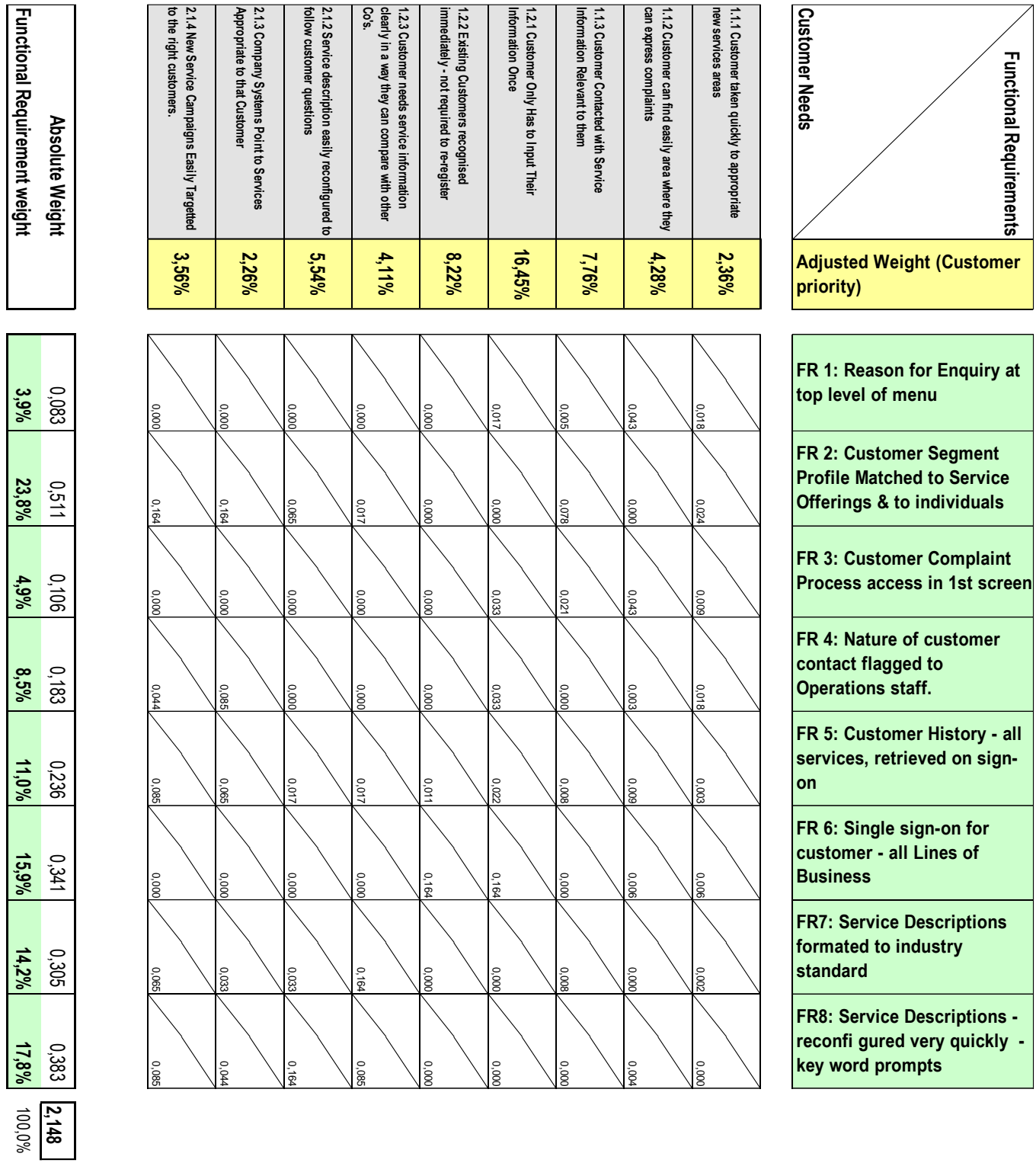

FR 1: Reason for Enquiry at top level of menu

FR 2: Customer Segment

Profile Matched to Service Offerings \& to individuals

FR 3: Customer Complaint

Process access in 1st screen

FR 4: Nature of customer

contact flagged to

Operations staff.

FR 5: Customer History - all services, retrieved on signon

FR 6: Single sign-on for customer - all Lines of

Business

FR7: Service Descriptions formated to industry standard

FR8: Service Descriptions reconfi gured very quickly key word prompts 


\subsubsection{Quality planning and design planning tables}

Additional information useful to product developers is often attached to the House of Quality to add application nuances to the analysis. The quality planning table adds customer perception competitive benchmarking and sales strategy for each customer need. The design planning table adds technical benchmarking and target specifications for each product requirement. Classical QFD attempts to quantify this information but shares the same ordinal scale math limitations, which can be fixed with AHP. Both tables can be simplified to qualitative information, as well. These tables are beyond the scope of this paper, but detailed guidance is provided in Parts 4 (ISO 16355-4:2016, 2016) and 5 (ISO 16355$5: 2016,2016)$ of the standard.

\section{Comprehensive QFD using Vector Profiles for Connecting Matrices}

In modern product development, especially in software, design decisions often transform into different underlying topics. For instance, the customer's need of ease-of-use transforms into the need for intelligent suggestions in an input mask, and these suggestions need collecting information about the user's preferences. The German QFD institute has published QFD best practices fitting particularly well to software product development (Herzwurm \& Schockert, 2006).

\section{Figure 9 Deming Value Chain for Software Project Deployment}

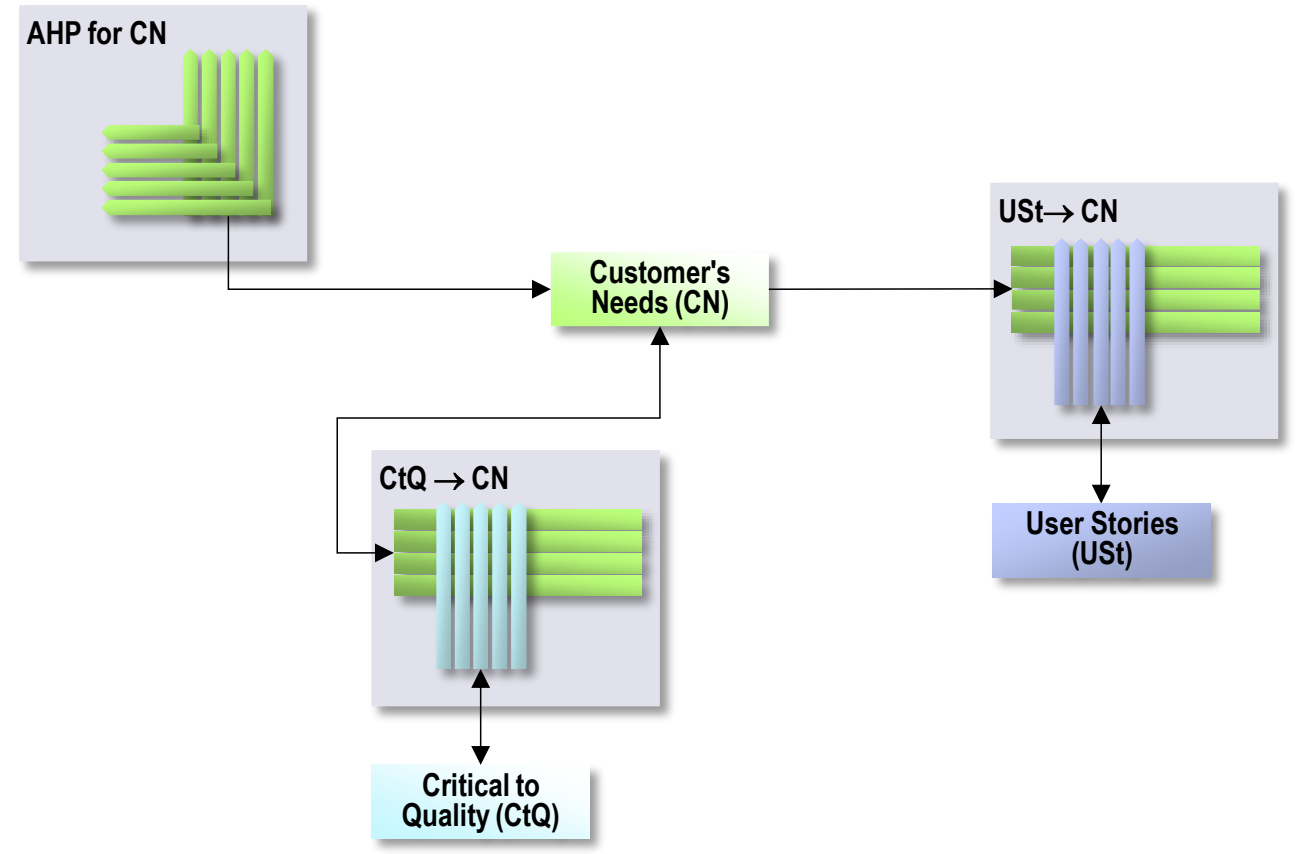

Since W. Edwards Deming published organizational deployment schemes for production chains in the early 1930'ies (Deming, 1986), such deployments are called Deming Chain. Prof. Akao used similar schemes for "QFD in the Broad Sense" (Akao, 1990). Deming Value Chains connect value-added production steps that transform resources into business value. 
In Figure 9, the Deming chain goes down some of the production steps typically used in software development. The starting point is an AHP analyzing priorities for customer needs. The needs are represented by a priority vector.

The customer's needs profile can be used in two ways. The left branch analyses the software process characteristics controlled by Critical-to-Quality (CtQ) characteristics. It uses a QFD matrix mapping $C t Q \rightarrow C N$, where the response of the software development process shall be the Customer's Needs $(\mathrm{CN})$. The right branch analyzes the functionality needed to fulfill the same customer's needs with User Stories (USt) as controls whose response are again Customer's Needs $(U S t \rightarrow C N)$. Both quality and functionality control software project success. Using the control profile of one QFD as the goal profile for the next QFD ultimately is based on the observation of Saaty, who understood that using ratio scale and vector profile makes the AHP hierarchy in decision making.

The Deming chain can be extended to include more ways of analyzing $\mathrm{CN}$, for instance, Voice of the Customer (Fehlmann \& Kranich, 2014) or New Lanchester Theory (Taoka, 1997). Since the priorities these methods produce are all profiles, they compare and can be combined. Moreover, additional steps such as testing can be added and controlled again by using profiles. Thus, the AHP way of using ratio scale and profiles to represent priorities allows for a sound way to implement Akao's vision of Comprehensive QFD (Figure 3). For a modern treatment of Deming chains, see (Fehlmann \& Kranich, 2016 - to appear).

\section{Conclusions}

Traditional QFD often happened to uncover the Eigenvector, if it was successful. This is not surprising as good QFD moderators developed a sixth sense for consistent QFD matrices. Every QFD Master Black Belt ${ }^{\circledR}$ student learns to distinguish suspicious matrices from sound ones. Now, it is clear how this worked. The key is using ratio scale, profiles instead of weights and sound mathematics when evaluating QFD matrices, as AHP always did.

The contribution of AHP to strengthening QFD is substantial, and now documented in all parts of ISO 16355. In 2007, Saaty was awarded the Akao Prize ${ }^{\circledR}$ for excellence in QFD by the co-

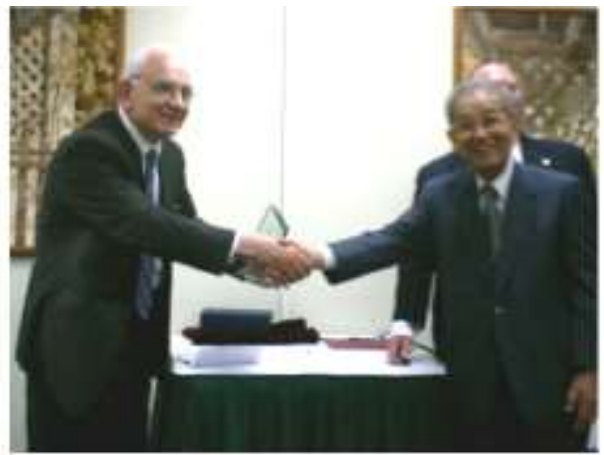

Dr. Akao presents Dr. Saaty with the International Akao Prize ${ }^{\circ}$ for his contribution to QFD, September 2007 founder of QFD, Yoji Akao.

\section{Key References}

Akao, Y., ed., 1990. Quality Function Deployment - Integrating Customer Requirements into Product Design. Portland, OR: Productivity Press.

Akao, Y., 1990. Quality Function Deployment: Integrating Customer Requirements into Product Design. Portland: Productivity Press.

Deming, W., 1986. Out of the Crisis. Center for Advanced Engineering Study ed. Boston, MA: Massachusetts Institut of Technology. 
Fehlmann, T. M., 2003. Linear Algebra for QFD Combinators. Orlando, FL, International Council for QFD (ICQFD).

Fehlmann, T. M. \& Kranich, E., 2014. Uncovering Customer Needs from Net Promoter Scores. Istanbul, Turkey, 20th International Symposium on Quality Function Deployment.

Fehlmann, T. M. \& Kranich, E., 2016 - to appear. Managing Complexity - Uncover the Mysteries with Six Sigma Transfer Functions. Berlin: Logos Verlag.

Herzwurm, G. \& Schockert, S., 2006. What are the Best Practices of QFD?. Tokyo, Japan, Transactions from the 12th Int. Symposium on Quality Function Deployment.

ISO 16355-1:2015, 2015. Applications of statistical and related methods to new technology and product development process - Part 1: General principles and perspectives of Quality Function Deployment (QFD), Geneva, Switzerland: International Standards Organization.

ISO 16355-2:2016, 2016. Applications of statistical and related methods to new technology and product development process - Part 2: Acquisition of Non-quantitative Voice of Customer and Voice of Stakeholder, Geneva, Switzerland: International Standards Organization.

ISO 16355-4:2016, 2016. Applications of statistical and related methods to new technology and product development process - Part 4: Analysis of Non-Quantitative and Quantitative VOC/VOS, Geneva Switzerland: International Standards Organization.

ISO 16355-5:2016, 2016. Applications of statistical and related methods to new technology and product development process - Part 5: Solution Strategy, Geneva Switzerland: International Standards Organization.

Johnson, C. \& Mazur, G., 2008. Value Based Product Development - Using QFD and AHP to Identify, Prioritize, and Align Key Customer Needs and Business Goals. Santa Fe, NM, Transactions from the 20th Symposium on Quality Function Deployment.

Mazur, G., 2014. QFD and the New Voice of Customer (VOC). Istanbul, Turkey, International Council for QFD (ICQFD), pp. 13-26.

Mizuno, S. \& Akao, Y., 1994. QFD: The Customer-Driven Approach to Quality Planning and Deployment. Tokyo: Asian Productivity Organization.

Nakui, S., 1987. Applying AHP to Weighting and Functional Classification in Function Deployment, Tokyo: Japan Society for Quality Control.

Oshiumi, K., 1966. Perfecting Quality Assurance System in Plants. Quality Control, May (supp.), pp. 62-67.

Saaty, T. L., 2003. Decision-making with the AHP: Why is the principal eigenvector necessary?. European Journal of Operational Research, Volume 145, pp. 85-91.

Saaty, T. L., 2007. The Analytic Hierarchy Process: How to Measure Intangibles in a Meaningful Way Side by Side. Ann Arbor, QFD Institute.

Saaty, T. L. \& Peniwati, K., 2008. Group Decision Making: Drawing Out and Reconciling Differences. Pittsburgh: RWS Publications.

Stansfield, K., Cole, J. \& Mazur, G. H., 2010. Complex IT Design using both Traditional $Q F D$ and Blitz $Q F D \circledR$. Ann Arbor, QFD Institute.

Suzuki, Y., 1972. Endeavor of Design Improvement for Large Diesel Engine for Ships. Quality Control, May special edition, pp. 16-20.

Taoka, N., 1997. Lanchester Strategy - An Introduction. Sunnyvale, CA: Lanchester Press Inc.. 